\section{Response to Dalal et al.}

To the Editor: It was not our intention to offend any medical professionals in India and certainly not to show the Indian medical community in a bad light, as suggested by Dalal et al. ${ }^{1}$ in their letter, "Prenatal Diagnosis in India Is Not Limited to Sex Selection" (this issue). We stated at the outset of our article that prenatal diagnosis (PD) is legitimately used in India for diagnosing a wide range of genetic diseases. We have also stated that selective feticide concerns only $2-4 \%$ of pregnancies carrying a girl, but the numbers are large in absolute terms. ${ }^{3}$ It is therefore unfortunate that Dalal et al. ${ }^{1}$ are offended by some of these statements. The statements in our review are amply supported by references to the vast number of papers and books published on the subject, $70 \%$ of which report work carried out in India by Indian authors. Below we address the points raised by Dalal and colleagues. ${ }^{1}$

Dalal et al. ${ }^{1}$ are offended by the statements "Prenatal diagnosis was introduced in India as a method for detecting fetal abnormalities, but was soon used mainly for prenatal sex selection. ${ }^{4,5}$ The Indian medical profession actively promoted it for this purpose..$^{6-9)}$ They claim that the second sentence is not true. We quote from four references, as follows. (i) "Eminent medical researchers who pioneered amniocentesis at the prestigious All India Institute of Medical Sciences advocated fetal sexing 30 years ago, arguing that it would assist those Indian women who repeatedly reproduce just to have a son.... Subsequently, sex selection was promoted as population control method. ... Doctors wanted the government to promote sex determination techniques to reduce population growth."' (ii) "Investigation ... showed that in a large public hospital in [Bombay] there had been 7800 requests for amniocentesis in the past five years. Only $5 \%$ were for detection of genetic defects and about $1 \%$ of women wanted to get rid of a male fetus. All the others sought amniocentesis with the express purpose of aborting female foetuses." (iii) "Eighty-four percent of gynecologists admitted to having performed amniocentesis tests for sex determination. ... The overwhelming majority of "patients". . were only interested in knowing the sex of the fetus." (iv) "Amniocentesis was first introduced in India in 1974. . . . It caught on like wildfire because right from the start, it was misused by doctors mostly

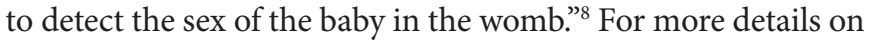
the role of the doctors, see refs. 4-13.

The book by Aravamudan, ${ }^{8}$ with a foreword by the former president of India, Abdul Kalam, gives an account of a 10-year field study in India. Large-scale involvement of medical professionals is indicated by the following. In the 1980s, almost $100 \%$ of 15,914 and 8,000 abortions in a Bombay abortion center and six city hospitals, respectively, were of female fetuses. ${ }^{5}$ Even after the Pre-Natal Diagnostic Techniques Act of 1994 banning the use of PD for sex selection, the child sex ratio has continued to deteriorate sharply, from 945 girls for every 1,000 boys in 1991 to 914 in 2011. The figures from the 2011 census, supported by a 15-year study published in The Lancet, ${ }^{3}$ show that the problem of skewed sex ratio has spread to nearly all the states in India. However, although the absolute number of individuals involved may be large, it probably forms a small proportion of medical professionals. Undoubtedly, the vast majority of medical professionals are in no way involved in illegal practices.

We examined the data to see whether we could find support for the suggestion that rape and crime against women in India ${ }^{7,11,14}$ and China ${ }^{15,16}$ may be related to the shortage of women. We did not find a correlation, except in 4 of 35 states. We did not state that crime against women is directly attributed to $\mathrm{PD}$ and sex selection.

Mention of both child marriages and dowry deaths is relevant. The exceptionally high rate of child marriages in India $(47 \%)^{17}$ contributes, however slightly, to further skewing of the sex ratio because of the high rate of death among teenage girls during childbirth; ${ }^{18}$ it also indicates the low status of women. One of the most stated reasons for selective abortions of girls is the dowry system. Dowry deaths indicate extreme situations, which cause even greater pressure for sex-selective abortions. With estimates of 15,000 to 25,000 per year, ${ }^{19}$ dowry deaths also contribute to the skewed sex ratio. We quoted the slogan used by medical professionals to advertise PD for sex selection in the 1980 s and 1990s. ${ }^{4,7,8,14}$ It is only by acknowledging these facts, not ignoring them, that one can hope to bring about change.

Dalal et al. ${ }^{1}$ are right in correcting us: The matriarchal system is not followed in all the southern states but only in parts of Kerala.

We did make an important novel suggestion to address the problem: compulsory targeted education addressing all aspects of the subject starting at a very young age in primary school and continuing until the end of secondary school. This may have the desired effect in 10-15 years and might be the quickest way to effect change in the culture.

At the time of the writing of our review in 2013, very little attention had been paid to this issue by politicians in India. We were therefore very pleased that during his Independence Day speech on 15 August 2014, the newly elected prime minister of India, Narendra Modi, directly addressed the question of the skewed sex ratio: "I request the doctors not to kill the girl growing in the womb of a mother just to line their own pockets. I advise mothers and sisters not to sacrifice daughters in the hope of [a] son." (The full text of Mr. Modi's speech is available at http://indiatoday.intoday.in/story/narendra-modiindependence-day-speech-full-text-red-fort/1/377299.html.) This is an encouraging sign. 


\section{DISCLOSURE}

The authors declare no conflict of interest.

\section{Kamlesh Madan, $P h D^{1}$ and Martijn H. Breuning, $M D, P h D^{1}$}

${ }^{1}$ Department of Clinical Genetics, Leiden University Medical Center, Leiden, The Netherlands. Correspondence: Kamlesh Madan (k.madan@lumc.nl)

\section{REFERENCES}

1. Dalal $A B$, Ranganath $P$, Phadke $S R$, et al. Prenatal diagnosis in India is not limited to sex selection. Genet Med 2015;17:88.

2. Madan K, Breuning MH. Impact of prenatal technologies on the sex ratio in India: an overview. Genet Med 2014;16:425-432.

3. Jha S, Kesler MA, Kumar R, et al. Trends in selective abortions of girls in India: analysis of nationally representative birth histories from 1990 to 2005 and census data from 1991 to 2011. Lancet 2011;377:1921-1928.

4. Allahbadia GN. The 50 million missing women. J Assist Reprod Genet 2002;19:411-416.

5. Tandon SL, Sharma R. Female foeticide and infanticide in India: an analysis of crimes against girl children. Int J Crim Justice Sci 2006. http://www.sascv.org/ ijcjs/previousissues.html. Accessed 8 August 2013.

6. George SM. Millions of missing girls: from fetal sexing to high technology sex selection in India. Prenat Diagn 2006;26:604-609.

7. Sharma BR, Gupta N, Relhan N. Misuse of prenatal diagnostic technology for sex-selected abortions and its consequences in India. Public Health 2007;121:854-860.

8. Aravamudan G. Disappearing Daughters: The Tragedy of Female Foeticide. Penguin Books: New Delhi, India, 2007.
9. Lancet India Correspondent. Misuse of amniocentesis. Lancet 1983; 321:812-813.

10. Subramanian SV, Corsi DJ. Can India achieve a balance of sexes at birth? Lancet 2011;377:1893-1894.

11. Oomman N, Ganatra BR. Sex selection: the systematic elimination of girls. Reprod Health Matters 2002;10:184-188.

12. Mudur G. Doctors in India prosecuted for sex determination, but few convicted. BMJ 2006;332:257.

13. Karat $B$, Gessorge $S$. Dont trash this law, the fault lies in non-implementation The Hindu, 4 February 2012. http://www.thehindu.com/opinion/op-ed/ dont-trash-this-law-the-fault-lies-in-nonimplementation/article2858004.ece. Accessed 8 August 2013.

14. Deshpande JD, Phalke DB, Phalke VD. Prenatal sex determination: issues and concerns. Pravara Med Rev 2009;1:4-6. http://www. pravara.com/pmr/pmr-1 -1-2.pdf. Accessed 8 August 2013.

15. Lai-wan CC, Blyth E, Hoi-yan CC. Attitudes to and practices regarding sex selection in China. Prenat Diagn 2006;26:610-613.

16. Hesketh T, Lu L, Xing ZW. The effect of Chinas one-child family policy after 25 years. N Engl J Med 2005;353:1171-1176.

17. UNICEF. UNICEF India Statistics, child protection 2012. http://www.unicef.org/ infobycountry/insdia_statistics.html. Accessed 8 August 2013.

18. ICRW. Child marriage facts and figures. The International Centre for Research on Women 2012. http://www.icrw.org/child-marriage-facts-and-figures. Accessed 8 August 2013.

19. Banerji R. Sex and Power Defining History, Shaping Societies. Penguin Books: New Delhi, India, 2008.

doi:10.1038/gim.2014.150 